\title{
A CASE HISTORY
}

The Ludwig Institute for Cancer Research is focused on translating research into cures. Helen Pearson investigates whether its sometimes unusual methods are producing results.

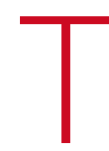

here were two phones on the Baltic island: one in the barn near where Webster Cavenee was seeking seclusion to write up a paper, the other on a village telephone pole. Both were ringing. When Cavenee ignored the first, the villagers brought him messages from the second: a mysterious American was trying to contact him from Brazil, then England, then Australia. He paid them no heed: "Calls from a guy I didn't know, from an organization I didn't know anything about - I thought he was a crank."

His paper finished, Cavenee flew home to Ohio, where he was working as a geneticist at the University of Cincinnati College of Medicine. As he opened his mail, the mystery caller rang again. "He said, 'I'm calling about the job. I understand you're interested', Cavenee recalls. "I said 'I don't know anything about your job'. He said 'No one's talked to you? We need to meet." The man told Cavenee to go to a Hilton near Chicago O'Hare airport, and ask the manager to take him to the boardroom. Intrigued, Cavenee did as he was told.

Good call. That meeting in 1984 changed Cavenee's life. A doctor called Hugh Butt from the Mayo Clinic in Rochester, Minnesota, one of whose patients was the billionaire Daniel Ludwig, offered the researcher US $\$ 3$ million a year for a new cancer research institute. "He was telling me they'd give me enough money that I could never blame failure on anyone but myself," Cavenee says. Cavenee accepted, and has worked for the Ludwig Institute for Cancer Research (LICR) ever since.

"You have to admit it's not the normal kind of job-recruitment process," says Cavenee. But then the LICR is not a very normal kind of research institute. Ludwig's legacy now supports Cavenee's research centre in San Diego, California, and eight more around the world (see 'Nine branches, seven countries'). It also - crucially, in the opinion of its leaders - spends between $15 \%$ and $20 \%$ of its annual \$100-million outlay on an infrastructure that deals comprehensively with intellectual-property issues and clinicaltrials management, and more on facilities that make some of the biological reagents that those trials require.

\section{Clinical discovery}

Those additional features are part of the LICR's formula for 'clinical discovery', a term that the chairman of the LICR's board of directors, Lloyd Old, prefers to the more modish 'translational research' and a goal he has pursued since the 1980s. In 20 years as the LICR's scientific director, and thus its effective chief executive, Old focused on strategies for getting cutting-edge science as close to the clinic as he could before turning it over to drug companies. $\sum_{\infty}$ "There is no question that we are the model," he says. "I don't know another organization that saw it so clearly and put it in place."

The LICR has indeed won itself some influential admirers, most recently collaborating with leaders at the National Medical Research Council in Singapore who are keen to tap into its infrastructure. It also has its critics. The centralized power structure that allowed Old

to put his vision of clinical discovery into place also allowed him to pursue his own particular scientific enthusiasms, a pursuit on which the jury is still out. And although clandestinefeeling meetings in hotel rooms are no longer part of the institute's recruitment procedure, its decisionmaking is still opaque enough for others to find it hard to see what they might most usefully copy.

The same whiff of the hermetic may also harm the LICR itself in its ability to recruit or retain the best in the field. "While the LICR has many strong attributes, there is a certain level of the old-boys' network," says Jim Woodgett, who worked for the LICR centre in London and now directs the Samuel Lunenfeld Research 


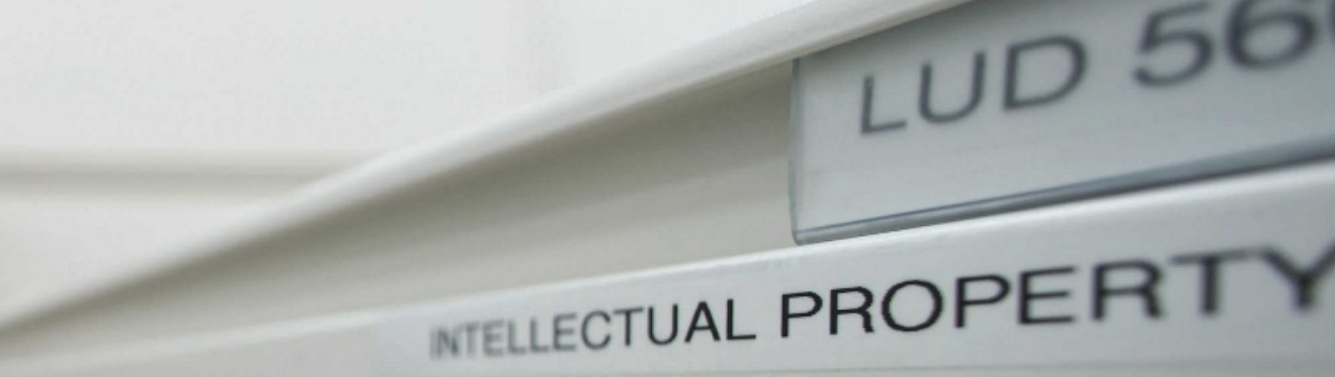

Institute in Toronto, Canada. "They should be willing to open themselves up to scrutiny."

A tendency to secrecy may be another part of the LICR's inheritance from Ludwig, a determined but publicity-shy entrepreneur who built up a tremendous fortune in shipping and other businesses. Why he decided to give so much money to cancer research is not known; one anecdote puts it down to oneupmanship. When Richard Nixon declared a 'war on cancer' in 1971 and requested an extra $\$ 100$ million for research, Ludwig, a friend of the president's, is said to have boasted "Hah, well I can beat that!" He founded the LICR that year with an endowment of slightly more than \$500 million.

Ludwig reputedly liked to do business with his friends, and relied on business and scientific directors from his inner circle, such as Butt, when it came to setting up the institute. In the first phase of its life that inner circle did the hiring and firing, selecting and approaching people such as Cavenee to establish institutes and then leaving them to pursue their own direction more or less autonomously. At this point some of the decisions reflected Ludwig's other interests: a branch in Brazil was connected to his massive land purchases in the Amazon. By the late 1980s and early 1990s, the institute had established an international reputation for sterling basic cancer research in areas such as signal transduction.

It was in 1988 that Old, initially recruited onto the LICR board while he was working at the Memorial Sloan-Kettering Cancer Center in
New York, became the LICR's scientific director. His interest in cancer was partly spurred by his family: his grandfather, mother, father and aunt all developed cancer. His lab at Sloan-Kettering played a part in some seminal discoveries, including the discovery of tumour necrosis factor (TNF), a molecule central to inflammation and cell death.

Now 75, Old is recovering from heart-bypass surgery in his Upper West Side Manhattan apartment, with parquet floors, a grand piano and French windows that open onto West End Avenue. Although no longer the LICR's scientific director, he is still the chairman of its board and wields considerable influence. His voice is soft and hoarse from having had a tube

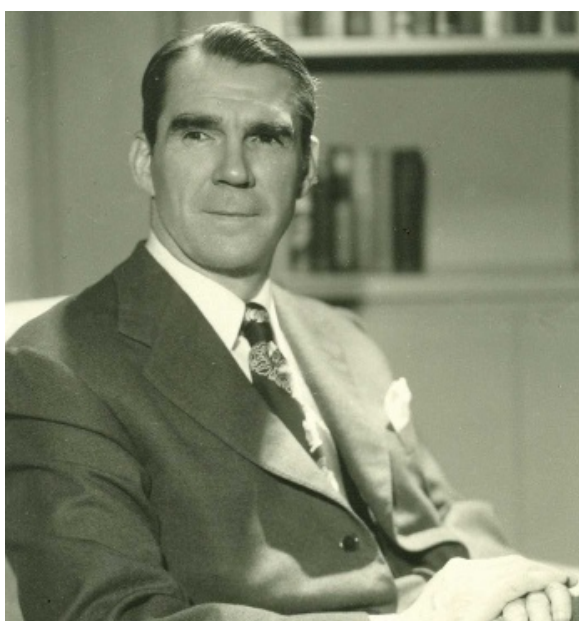

Daniel Ludwig's legacy: focused and well financed. down his throat, his hands shake and he has a tendency to ramble. But he leans forward excitedly when he talks about his passions, such as $\varangle$ translational research and searching for the secrets of the immune system's successes - and failures - in fighting off cancer.

Old says he faced obstacles when he tried to carry out clinical work related to his discoveries at Sloan-Kettering. When he came in as the LICR's scientific director, "I wanted to create structures that I would have liked to be there for me when I came along." He set about making the rest of the organization take that desire on board. "Old said to the institute's branches, 'You do it or else", says Eric Hoffman, who directs the LICR's Office of Clinical Trials Management.

\section{Control is key}

Old's mantra, taken up by his colleagues, has been that the key to translational research is control. 'Control' means retaining the intellectual-property rights and having a support staff that allows LICR researchers to do at least some early-phase clinical trials, rather than leaving a treatment's post-lab life entirely in the hands of pharmaceutical companies. That sort of control has made the institute one of the largest not-for-profit DNA patent holders in American biomedicine. It also means that LICR researchers can design trials to investigate a therapy's mechanisms, rather than just its performance or lack of it. That lets them explore speculative applications that would be ignored by a drug company with more obviously promising leads to hand. "That gives us immense power to get the job done," says Jonathan Skipper, director of intellectual property at the LICR. "You're not beholden to anyone" "They can do these wacky things and demonstrate proof of concept for something new," says Paul Bevan at biotech company Wilex in Munich, Germany, who is collaborating with the LICR.

The idea is not to go it alone without pharmaceutical companies. It is to get therapies far enough down the road under the institute's control that they will be in pole position for transition to the clinic. "In many cases when you license it you lose control," says Joseph Tomaszewski, who is involved in translation of cancer discoveries at the National Cancer Institute (NCI) in Bethesda, Maryland. "So you want to take it as far forward as you can."

The other aspect of the LICR's 'control' is ensuring that researchers have access to their own supply of the physical reagents needed for their trials. The LICR owns facilities in Melbourne, Australia, and Ithaca, New York, dedicated to the production and storage of antibodies and other biological reagents. "Synthesizing a monoclonal antibody that can be put in humans 
can cost a million dollars or more, a very expensive and tedious procedure that academic institutions usually can't afford," says Otmar Wiestler, chairman of the German Cancer Research Center, Heidelberg, who works with the the LICR. "The LICR is really unique in providing such an incredible infrastructure," he goes on. "I don't know any other academic institution that does it on this scale."

Take the institute's work on cancer vaccines that might provoke the immune system into z killing tumours. Since the early 1990s, Thierry Boon, director of $\varangle$ the LICR's Brussels branch, Old and others have identified a family of 'cancer/testis' antigens that are expressed almost exclusively in tumour cells and not healthy tissues. The LICR has agreements with GlaxoSmithKline to work on the commercial development of these and other antigens. But the institute has also retained the right to perform clinical trials itself, and the ability to make its own antigens to that end. Vincent Brichard, who deals with the vaccine effort for Glaxo-

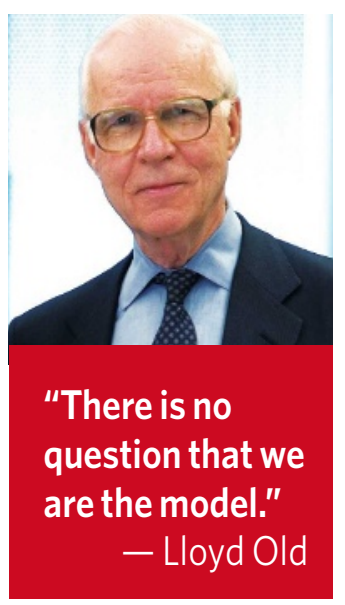

characterized its behaviour, hoping it might have a therapeutic role.

Chaitanya Divgi, who once worked in Old's lab at the LICR, and is now at the University of Pennsylvania in Philadelphia, wanted to test the idea that the antibody could be used to identify which kidney masses are malignant clear-cell carcinoma as opposed to other, less dangerous tumours. This is something that currently requires surgery and a biopsy. It was not one of the applications being pursued by Wilex, the company to which the antibodies are licensed by the LICR, so the LICR funded an independent trial. Divgi showed that the antibody attached to kidney masses in 15 out of 16 patients who were subsequently found to have clear-cell renal carcinoma - and in none of those whose kidney masses were more benign ${ }^{1}$. A commercial assessment spurred by these results has convinced Wilex to launch a phase III trial of G250 as a diagnostic agent alongside its trial on the antibody as a possible therapy for reducing recurSmithKline in Rixensart, Belgium, agrees that trials performed by the LICR tackle scientific questions that have not figured in GlaxoSmithKline's development programme, but may yet prove crucial in the company's decision to develop an antigen.

A monoclonal antibody called G250 provides another example of the Ludwig approach. G250, which was discovered not by LICR researchers but at the University of Leiden in the Netherlands, binds to clear-cell renal carcinoma, a common and aggressive form of kidney cancer. Old's lab did much of the work that

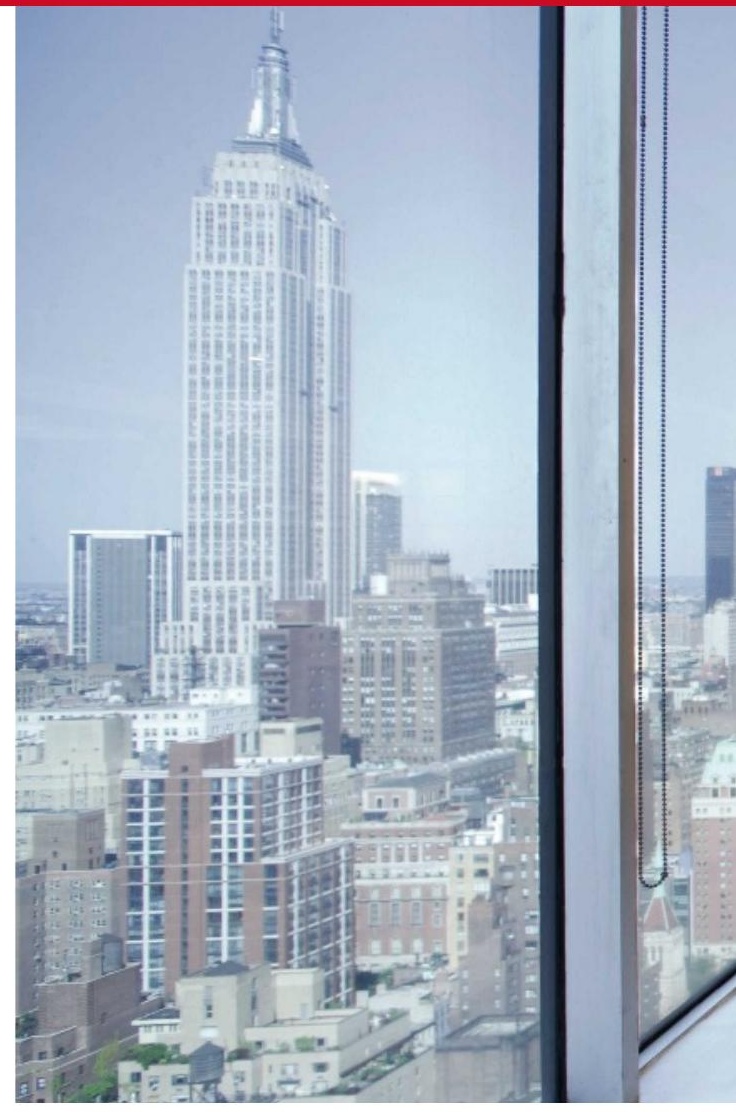

frustrating or overwhelming to many — getting a satisfied buzz out of rules and regulations takes a certain type. And the LICR has employed 15 such types to deal with clinicaltrial paperwork alone.

The LICR owes this infrastructure not just to Old's vision; the "historically privileged position", as Old puts it, of the institute's bank balance is crucial. Its endowment of $\$ 1.4$ billion is not in the same league as those of the Wellcome Trust, the Howard Hughes Medical Institute, or the Bill \& Melinda Gates Foundation. But it is substantial, focused on cancer and entirely under the control of a board of like-minded trustees: there is no peer-review process. Old and Andrew Simpson, who has succeeded him as scientific director, suggest that other institutions in privileged positions - such as Harvard, with its $\$ 34$ billion endowment - could learn something from the LICR's model. (In May, Harvard announced that it would be receiving $\$ 117.5$ million over 5 years from the National Institutes of Health in Bethesda, Maryland, for a new centralized translational research effort in which the university is concomitantly investing \$15 million annually.) But the LICR is hardly proselytizing. The only time that the central office has published anything about its vision and infrastructure was in a 2004 letter to Nature Medicine ${ }^{2}$. Old says he "was taught not to toot his own horn", although perhaps he is now overcoming that childhood stricture a little.

Becoming modesty can edge into opacity. It is unclear, even to some of those who work for the organization, how top-level decisions are made and priorities set. "It's fairly autocratic in the way it's run," says Gerard Evan, who worked at the now defunct Cambridge, UK, branch 
